\title{
Young general practitioners' professional activities: a survey in the French-speaking part of Belgium
}

\author{
Anne-Laure Lenoir, Lou Richelle, Frédéric Ketterer, Bénédicte Fraipont, \\ Marion Cayn, Christiane Duchesnes \& Sophie Leconte
}

To cite this article: Anne-Laure Lenoir, Lou Richelle, Frédéric Ketterer, Bénédicte Fraipont, Marion Cayn, Christiane Duchesnes \& Sophie Leconte (2017): Young general practitioners' professional activities: a survey in the French-speaking part of Belgium, Acta Clinica Belgica, DOI: 10.1080/17843286.2017.1302624

To link to this article: http://dx.doi.org/10.1080/17843286.2017.1302624

Submit your article to this journal $₫$

View related articles $\sqsubset$

View Crossmark data $₫$ 


\title{
Young general practitioners' professional activities: a survey in the French-speaking part of Belgium
}

\author{
Anne-Laure Lenoir ${ }^{1}$, Lou Richelle ${ }^{2}$, Frédéric Ketterer ${ }^{1}$, Bénédicte Fraipont ${ }^{3}$, \\ Marion Cayn², Christiane Duchesnes ${ }^{1}$, Sophie Leconte ${ }^{3}$
}

${ }^{1}$ Département de Médecine Générale Université de Liège, CHU du Sart-Tilman, Liège, Belgium, ${ }^{2}$ Département de Médecine Générale Université libre de Bruxelles, Campus facultaire Erasme, Bruxelles, Belgium, ${ }^{3}$ Centre Académique de Médecine Générale Université, Bruxelles, Belgium

Introduction: This study described the professional activities of graduates of the Advanced Master of General Practice of the Belgian French-speaking universities from 1999 to 2013 and identified factors influencing their situation.

Methods: Between November 2014 and June 2015, all graduates were asked to complete a questionnaire concerning their professional activities. The first part of the analysis described the respondent's socio-demographic and professional characteristics. The second part aimed at detecting possible factors influencing GPs' professional situation.

Results: The main results of the study showed that $78.5 \%$ of graduates still worked as GPs and $21.5 \%$ left and had another activity. The way graduates worked in General Practice was also highly diverse in terms of both working time and types of activities. Only a minority of them were exclusively performing General Practice (8.5\%). $45.8 \%$ of GPs worked part-time, and were more commonly women and GPs in group practice. This survey confirmed feminisation of the profession and increasing work in associations. Among factors influencing retention in General Practice, preference for specialising in General Practice at time of graduation in medicine and duration of practice influence retention in practice.

Conclusion: Our survey put the emphasis on the evolution of practice: job and vocational training planning should not be performed based only on previous generations. There is no one predefined way to practise; the blurred boundaries of General Practice activities do not allow for the drafting of a reference frame that could help workforce planning.

Keywords: General practitioners, Professional practice, Young generation, Regional health planning

\section{Introduction}

In European countries, primary care faces many challenges that require a suitable workforce. ${ }^{1}$ However, recruitment and retention in the profession of primary care workers is difficult. ${ }^{2}$ This prompted many European countries to focus on medical workforce planning and encouraged the European Commission to create the Joint Action on European Health Workforce Planning and Forecasting in 2013.

Belgium is also confronted with these workforce difficulties. ${ }^{3}$ In July 2016, the Office of Employment officially considered General Practice as a shortage occupation in Wallonia, part of the French-speaking part of Belgium. ${ }^{4}$ For a long time, General Practice seemed less attractive to students than other medical specialties. ${ }^{5}$ For those certified

Correspondence to: Anne-Laure Lenoir, Département Universitaire de Médecine générale ULg, CHU du Sart-Tilman, bâtiment B23 4000 Liège,

Belgique. Email: allenoir@ulg.ac.be as General Practitioners (GPs), only $66.5 \%$ are considered active (i.e. they performed at least 500 contacts a year or for salaried physicians were working at least 0.1 fulltime) by the National Institute for Health and Disability Insurance (NIHDI). ${ }^{5}$ Furthermore, among these active GPs, 34\% are aged 54-65 years, while barely $25 \%$ are younger than 45 . Young graduates may not be sufficient in number to balance the retiring GPs. ${ }^{6}$

A further difficulty in workforce planning is that General Practice is undergoing profound changes. There are demographic changes, with a decreasing number of GPs and an increasing ratio of female GPs in most European countries. ${ }^{6}$ There exists also a change in the way GPs organise their work, with reduced working time especially among younger practitioners..$^{3,7}$

In Belgium, there is no consensual definition of general practice. Some activities are part of general practice for some people and not for others. The available data of 
NIHDI, based on the number of medical acts charged to the social security, do not offer an insight of the performed activities; moreover they do not allow for individual working time to be evaluated. ${ }^{6}$

The aim of the survey was to describe the professional activities of young graduates holding an Advanced Master of General Practice and identify factors influencing their professional situation and therefore workforce planning. Researchers of the three French-speaking universities of Belgium - Université Catholique de Louvain (UCL), Université Libre de Bruxelles (ULB) and Université de Liège (ULg) - conducted this study.

\section{Methods}

The three Belgian French-speaking universities provided the lists of their graduates of the Advanced Master of General Practice from 1999 to 2013; they defined the study population. 1999 was the first year of graduation in the Advanced Master of General Practice in Belgium.

The questionnaire, designed by the research team, included two parts. The first part concerned socio-demographic parameters. The second part addressed professional activities. The team created a list of medical activities a GP may perform, or asked for the professional activity if it was not a medical one. Further questions for graduates who were currently working in General Practice concerned the organisation of their practice (working time, types of activities, kind of practice, etc.). Few open questions required short answers such as an hour or a name of activity. Six GPs pretested the questionnaire for its feasibility and understandability. No major adjustment was necessary.

The questionnaire was not anonymous. Anonymisation of the data took place before the analysis. Researchers informed participants that access to their data was restricted to the research team.

The survey took place between November 2014 and June 2015. Researchers personally contacted potential participants by phone or email to obtain their consent to participate. Those who agreed were able to complete the questionnaire themselves (online or paper version of the questionnaire) or indirectly (by phone interview with a researcher completing the online questionnaire, transcribing what the respondent said).

A coding scheme was carried out to establish the database. The coding of open questions was performed retrospectively based on responses. The first part of the analysis was meant to describe the respondent's sociodemographic and professional characteristics with basic sorting, cross-sorting and chi square. The second part aimed at detecting possible factors influencing GPs' professional situation through cross-tabulation.

One of the main features of General Practice in Belgium is the combination of consultations at the GP's office and home visits. Therefore, in this study, GPs were respondents reporting at least one weekly hour dedicated to consultations and home visits.

\section{Table 1 Respondent's characteristics}

\begin{tabular}{llcc}
\hline Variable & & $\%$ & Headcount $^{\mathrm{a}}$ \\
\hline Sex & Men & 35.3 & 438 \\
& Women & 64.7 & 802 \\
Preference of & General practice & 86.1 & 1065 \\
specialisation at & Another & 13.9 & 172 \\
time of graduation & specialisation & & \\
in medicine & & & \\
Professional activity & General practice & 78.5 & 972 \\
at the time of the & Other medical & 18.6 & 230 \\
survey & activities & & \\
& No medical & 2.9 & 36 \\
& activity & & \\
\hline
\end{tabular}

Non-respondents were excluded.

Table 2 Distribution of participants according to weekly working time and working time percentage dedicated to GP

\begin{tabular}{lcccc}
\hline & & \multicolumn{3}{c}{ Weekly working time dedicated } \\
& & \multicolumn{3}{c}{ to GP } \\
\cline { 3 - 5 } & & $\mathbf{3} \mathbf{3} \mathrm{h}$ & $\mathbf{> 3 8} \mathrm{h}$ & Total \\
\hline Working time & $\mathbf{5 7 5 \%}$ & 13.0 & 1.9 & 14.9 \\
percentage dedi- & $\mathbf{7 5 \%}$ & 30.9 & 54.2 & 85.1 \\
cated to GP & Total & 43.9 & 56.1 & $100 \%$ \\
& & & & 915 \\
\hline
\end{tabular}

During the analysis, we categorised GPs according to their working time in General Practice. We chose two criteria to define a full-time practice: the weekly working time and the percentage of the working time dedicated to General Practice. The lower limit value for weekly working time was $38 \mathrm{~h}$ because, in Belgium, it corresponds to a full-time job of a salaried worker. Based on responses, we realised some respondents declared a percentage of time for General Practice and a percentage of time for administrative duties while others declared $100 \%$ General Practice (implicitly including the administrative work). Without knowing more, we decided to set the limit value of the working time dedicated to General Practice at 75\%, to try to keep homogeneity between respondents' answers.

According to our criteria, the full-time practice corresponded to a minimum of $38 \mathrm{~h}$ of weekly working time of which at least $75 \%$ was dedicated to General Practice. All other modalities corresponded to part-time General Practice.

The statistical analysis was performed using SAS software with a significance level of 5\%.

This study was approved by the ethical committees of the 3 universities involved (UCL 2014/517, ULB 2014/437, ULg B707201422436).

\section{Results}

1721 doctors graduated with an Advanced Master of General Practice between 1999 and 2013 in the Belgian French Community. 1240 individuals participated in the current study (72.0\%). The response rate varied from 61.2 to $83.5 \%$ according to the year of graduation. The characteristics of the participants are presented in Table 1.

Women were predominant in our study (64.7\%), which reflects their ratio in the Advanced Master of General Practice graduates' list. 
Table 3 Distribution of GPs' working time by sex

\begin{tabular}{llcccc}
\hline & \multicolumn{4}{c}{ Working time } \\
\cline { 3 - 6 } & & Full-time & Part-time & \multicolumn{2}{c}{ Total } \\
\hline Sex & Women & 46.7 & 53.3 & $100 \%$ & 585 \\
& Men & 67.6 & 32.4 & $100 \%$ & 330 \\
& Total & 54.2 & 45.8 & $100 \%$ & \\
& & & \multicolumn{3}{c}{915} \\
& & & 0 & 0.0001 \\
\hline
\end{tabular}

Graduates currently working in General Practice At the time of the survey, $78.5 \%$ of graduates worked in General Practice.

The reported average working time of GPs was $45.8 \mathrm{~h}$ a week (SD $14.2 \mathrm{~h}$.) including $39.8 \mathrm{~h}$ (SD $12.9 \mathrm{~h}$ ) of consultations and home visits. The residual time concerned other professional activities (e.g. administrative tasks).

There was a lot of diversity in GP activities between respondents. Some GPs (1.9\%) had a high working time but spent a small percentage of that time in General Practice. Others $(30.9 \%)$ were mainly $(>75 \%$ of their working time) involved in consultations and home visits but worked only a few hours a week. According to our criteria, $54.2 \%$ of GPs are full-time GPs while $45.8 \%$ worked part-time in General Practice. (Table 2).

A statistically significant correlation $(p<0.0001)$ was found between working time and sex (Table 3). Proportionally women more frequently worked part-time $(53.3 \%)$ than men $(32.4 \%)$.

Regarding practice organisation (Table 4), 67\% of GPs worked in mono- or multidisciplinary associations. Solo practices were decreasing in number $(48.9 \%$ of graduates between 1999 and 2002, only $18.1 \%$ of graduates between 2010 and 2013). Conversely, multidisciplinary associations seemed to be on the rise $(40.3 \%$ of graduates between 2010 and 2013, only $16 \%$ of graduates between 1999 and 2002). During the same period, mono-disciplinary associations were characterised by stability in the proportion of graduates who had chosen this kind of practice.

A significant association exists between the type of practice and the working time $(p<0.0001)$ (Table 5). It appeared that GPs practising in multidisciplinary associations were more likely to work part-time (73.4\%), while doctors in solo practice $(27.4 \%)$ or in mono-disciplinary associations (39.3\%) frequently worked full-time.

Various activities were performed by GPs. $91.5 \%$ of GPs exercised at least one other medical activity. Among them, 56.7\% had at least two other activities. The most common activity (83.4\%) was out-of-hours medical care. The other medical activities often exercised by GPs were consultations for mother and child health at the Office of Birth and Childhood, consultations in family planning centres, coordination in nursing homes, health promotion at school, hospital activities, sampling in laboratories, nutrition consultations, sport medicine consultations, consultations in addiction centres and occupational health (Figure 1). 8.7\% of GPs also had non-medical activities such as political and medical administration activities, teaching, research, organisation of continuing medical education.

\section{Graduates not practising GP}

Among the $21.5 \%$ of graduates who were not performing General Practice at the time of the survey, $86.5 \%$ (i.e. $18.6 \%$ of the study population) exercised other medical activities. Most of them had hospital activities (58.7\%) usually associated with out-of-hours hospital activities. Occupational health $(11.7 \%)$ was the second most frequent activity and was usually the only activity. Others frequently combined several activities.

$13.5 \%$ (i.e. $2.9 \%$ of the study population) of graduates not practicing GP also undertook no medical activities.

\section{Factors influencing retention in General Practice}

Preference for specialising in General Practice at time of graduation in medicine and duration of practice had an influence on retention in practice.

Choosing or not specialising in General Practice influenced the number who stayed in practice $(p<0.0001)$. Indeed, of the graduates who had chosen a General Practice specialisation $82.6 \%$ continued their practice, while of those who had not chosen a GP specialisation as first choice only $52.9 \%$ continued (Table 6 ).

Proportionally more old graduates had left the practice ( $p<0.0001$ ). (Table 7): $31.8 \%$ of graduates in 1999-2005 period left GP practice while only $7.9 \%$ of those who graduated in 2010-2013 period (and 15.7\% for the intermediary period).

The sex has an effect on retention in practice $(p=0.0231)$ (Table 8). A larger percentage of men still exercised General Practice (82.1 vs. $76.6 \%$ for women).

Table 4 Type of practice regarding the years of GPs' graduation

\begin{tabular}{|c|c|c|c|c|c|c|}
\hline \multirow[b]{3}{*}{ Years of graduation } & \multirow{7}{*}{$\begin{array}{l}\text { 1999-2002 } \\
\text { 2003-2005 } \\
\text { 2006-2009 } \\
\text { 2010-2013 } \\
\text { Total }\end{array}$} & \multicolumn{5}{|c|}{ Type of practice } \\
\hline & & \multirow{2}{*}{$\begin{array}{r}\text { Alone } \\
48.9\end{array}$} & \multirow{2}{*}{$\begin{array}{c}\text { In mono disciplinary } \\
\text { association }\end{array}$} & \multirow{2}{*}{$\begin{array}{c}\text { In multi-disciplinary } \\
\text { association }\end{array}$} & \multicolumn{2}{|c|}{ Total } \\
\hline & & & & & $100 \%$ & 219 \\
\hline & & 45.9 & 27.9 & 26.2 & $100 \%$ & 183 \\
\hline & & 27.2 & 39.2 & 33.6 & $100 \%$ & 250 \\
\hline & & 18.1 & 41.6 & 40.3 & $100 \%$ & 293 \\
\hline & & 33.0 & 36.8 & 30.2 & $100 \%$ & 945 \\
\hline
\end{tabular}


Table 5 Distribution of GPs' working time, according to the type of practice

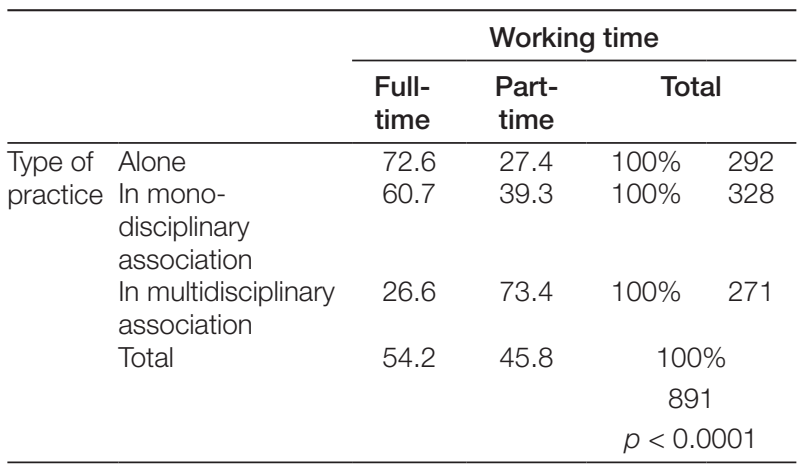

\section{Discussion}

The main results of our study showed that $78.5 \%$ of graduates still worked as GPs and $21.5 \%$ left and had another activity. The way graduates worked in General Practice was also highly diverse in terms of both working time and types of activities. $45.8 \%$ of GPs worked part-time and only a minority of them were exclusively performing General Practice (8.5\%).

The rate of graduates not working in General Practice is quite similar to that revealed by the NIHDI statistics ${ }^{6}$ : according to this institute, among those under 45 years, the rate of inactive GPs is $18.1 \%$ for Belgium and $24.3 \%$ for Brussels and Wallonia (21.5\% in our study). It is noteworthy that among the graduates who left General Practice, the majority of graduates remained active in health care. In 2003, Van Baelen ${ }^{8}$ showed that $30 \%$ of GPs left the profession within five years of graduating. Among them, only a minority (2.7\%) practised no medical activities. This was confirmed, in 2007 , by V. Lorant ${ }^{9}$ who showed that $1.5 \%$ of all GPs practised no medical activities. Graduates who practised no medical activities at the time of our survey totalled $2.9 \%$.

Choosing to specialise in General Practice at the time of graduation in medicine was an important factor influencing the number who stayed in General Practice. Van Baelen ${ }^{8}$ drew the same conclusion in her study.
The definition of active GPs influences the results that may not be fully comparable to other surveys. In our study, active GPs were reporting at least one hour of weekly working time dedicated to consultations and home visits. For the NHIDI active GPs perform at least 500 contacts a year or for salaried physicians are working at least 0.1 full-time. ${ }^{6}$ So there will be more active GPs in our study. From another perspective, some GPs declare contacts with General Practice nomenclature codes for no such activities e.g. for consultations in sports medicine or nutrition. These activities were recorded as acts of General Practice by the NIHDI, but they were not recorded in our survey. In this case the number of active GPs will increase for the NIHDI compared to our study.

The choice we made to define active GPs is linked to the objective of the study, i.e. General Practice workforce. It does not take into account the other activities exercised by GPs, such as consultations for the Office of Birth and Childhood or in family planning centres. Workforce planning in General Practice should evaluate needs in General Practice and needs in other activities. Indeed, the other activities are also important in the Belgian health care system.

The approach taken to working as a GP is very different from one graduate to another. We therefore define a full-time GP by taking into account the weekly working time and the working time percentage dedicated to General Practice. According to these criteria, only $54.2 \%$ of GPs practised full-time. The part-time GPs were more commonly women and GPs in group practices. It's coherent with the results of B. Schoenmakers who showed in 2014 that, in Flanders, a full-time job is more often practiced by men and solo GPs. ${ }^{10}$

Limits may also occur in the definition of a full-time job. The NIHDI calculated the full-time job ${ }^{6}$ with the reference of the work of GPs aged 45 to 54 years, i.e. the age group in which they consider that the professional activity is the most important. The decision of the NIHDI to select as a reference a population at the peak of its activity is interesting. However, this population predominantly comprises men practising solo; this does not correspond

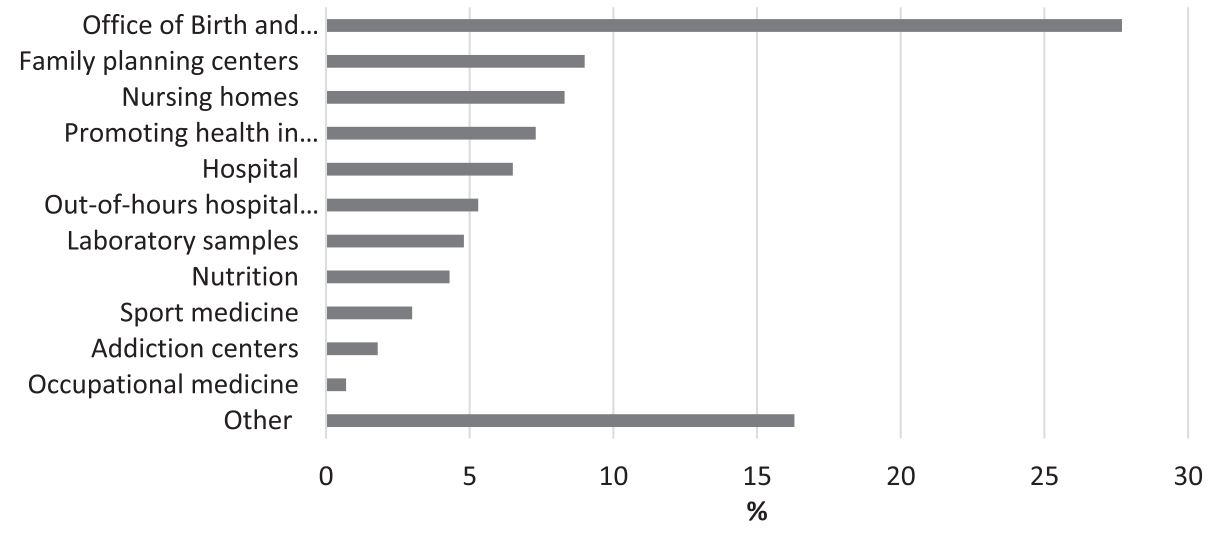

Figure 1 Further medical activities exercised by GP (except out-of-hours medical activities). 
Table 6 Influence of the choice of specialisation on retention

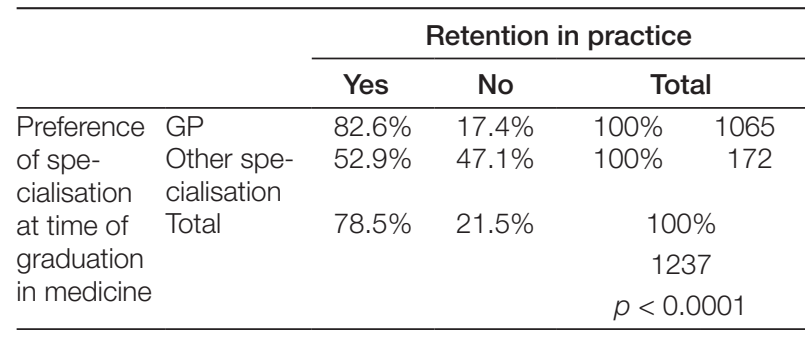

Table 7 Influence of the year of graduation on retention

\begin{tabular}{llrrrr}
\hline & \multicolumn{3}{c}{ Retention in practice } \\
\cline { 3 - 6 } & & Yes & \multicolumn{1}{c}{ No } & \multicolumn{2}{c}{ Total } \\
\hline Year of & $1999-2005$ & $68.2 \%$ & $31.8 \%$ & $100 \%$ & 603 \\
graduation & $2006-2009$ & $84.3 \%$ & $15.7 \%$ & $100 \%$ & 305 \\
& $2010-2013$ & $92.1 \%$ & $7.9 \%$ & $100 \%$ & 329 \\
& Total & $78.5 \%$ & $21.5 \%$ & $100 \%$ & \\
& & & & 1237 & \\
& & & & 0.0001 \\
\hline
\end{tabular}

Table 8 Influence of the sex on retention

\begin{tabular}{llcccc}
\hline & \multicolumn{4}{c}{ Retention in practice } \\
\cline { 3 - 6 } & & Yes & No & Total & \\
\hline \multirow{2}{*}{ Sex } & Women & $76.6 \%$ & $23.4 \%$ & $100 \%$ & 802 \\
& Men & $82.1 \%$ & $17.9 \%$ & $100 \%$ & 436 \\
& Total & $78.5 \%$ & $21.5 \%$ & $100 \%$ & \\
& & & 1238 & \\
& & & $p=0.231$ & \\
\hline
\end{tabular}

to following generations. Our limit value of 38 weekly hours dedicated to GP corresponds to the full-time job of a salaried worker. However, it may seem insufficient when it is common to see GPs working for more than $60 \mathrm{~h}$ a week.

Indeed, the young generation of GPs is mainly composed of women. The feminisation of GP is a global trend. Statistics from the Belgian Social Security ${ }^{6}$ confirm this tendency: women represent $64.5 \%$ of GPs under 45 years, and $30.4 \%$ of GPs aged 45 to 65 . The results of our study correspond to these data with a ratio of women GP of $64.7 \%$. The feminisation has modified the traditional model of professional organisation because women have developed strategies to adapt their working time to the requirements of their private life. ${ }^{12}$ However, even if they still work fewer hours than men, ${ }^{11}$ the difference between women and man concerning the working time tends to decrease. ${ }^{12}$ Whatever the sex, young GPs regulate their working time to maintain a good quality of life and balance work and private life. ${ }^{13,14}$ Moreover, in a study performed in England in 2014 results proved that many GPs worked part-time because they found that clinical work became more complex, especially because of aging of population. ${ }^{15}$ Doing so, they could provide good quality of care.

Young GPs tend to practise together more than their elders do; multidisciplinary association practice is favoured because part-time work is more common.
As feminisation and practice in association are increasing, we can assume that part-time work will grow in the future. The workforce planning cannot be calculated based on previous generations.

Concerning the organisation of their professional activities, our results showed that the majority of young GPs varied their professional activities. In 2014, in Flanders, B. Schoenmakers found that $60 \%$ of Flemish GPs had at least a second activity. ${ }^{10}$ The versatility of the diploma offers young graduates various opportunities and/or functions. ${ }^{16}$ The practice of activities other than General Practice results from a desire for diversification, ${ }^{17}$ a determination to increase expertise or the exploration of activities to find a personal way of working. ${ }^{12}$

In her work, G. Bloy ${ }^{18}$ describes several types of career among graduates in General Practice. The 'loyals' are characterised by a linear trajectory with the intentions expressed at the time of training. Among them, she distinguishes three populations. The graduates who chose General Practice by inclination and followed this path for the long term. Others who chose General Practice in order to pursue another specific discipline after graduation, such as sports medicine or nutrition. Finally, those who failed in another specialty did not want to work in General Practice and tried to go back to their first idea. In our study, we saw that the first choice of another specialty is a reason for leaving General Practice. This typology underlines the difficulty in understanding a phenomenon: the reality is complex, and reducing the decision to choose a particular type of work to only one or two reasons is not possible.

Other graduates either changed their mind because they discovered a more appealing activity, or had the opportunity to reduce working hours, or after a disappointing period of practice as a GP. These reasons apply not only to a complete change of career but also to making adjustments to professional practice.

Data collection affects the interpretation of the results. Indeed, using a short questionnaire after a first contact allowed us to achieve a very good response rate (72\%) and to present a realistic picture of professional activities among young GPs. However, we could not find some graduates. This could be a sign that these graduates were no longer practising medical activities. Therefore, we should interpret these results with caution even if the comparison with Belgian literature suggests that we are quite close to the reality.

Furthermore, the objective of the survey was to describe the professional activities of young graduates in General Practice. The questionnaire was not designed for extended statistical analysis. Moreover, conducting a statistical analysis of the professional career of a graduate is questionable from an epistemological point of view because the concept of 'career' suggests a dynamic and evolving process. Using a questionnaire means taking a picture of a situation at a certain time. We should bear in mind that professional activities can change as a function 
of individual socio-biographical events. ${ }^{19,20}$ For instance, GPs may work part-time because they have small children, which require time and job flexibility. However, once their children grow older, they might work fulltime. This quantitative study will thus be followed by interviews with some graduates in order to gain a more comprehensive understanding of factors influencing their professional career and choices.

\section{Conclusion}

This study highlights some elements that could affect the numbers that stay in General Practice. A positive choice for General Practice during the medical degree is one of them.

The survey confirmed feminisation of the profession, increasing work in associations as well as part-time as defined in this survey.

As far as General Practice workforce planning is concerned, our survey put the emphasis on the evolution of practice: planning should not be performed only based on previous generations. Individual paths are not linear and respond to biographical events. Finally, there is no one predefined way to practise; the blurred boundaries of General Practice activities do not allow for the drafting of a reference frame that could help workforce planning.

\section{Disclosure statement}

\section{Funding}

This work was supported by the 'Centre de Coordination Francophone pour la Formation en Médecine Générale (CCFFMG)'.

\section{Notes on contributors}

Anne-Laure Lenoir, Lou Richelle, Bénédicte Fraipont, Marion Cayn are GPs. Frédéric Ketterer is a sociologist and full researcher. Christiane Duschesnes and Sophie Leconte are GPs and senior researchers.

\section{Conflict of interest}

No potential conflict of interest was reported by the authors.

\section{References}

1 Kringos D, Boerma W, Hutchinson A, Saltman R. Building primary care in a changing Europe. World Health Organization on behalf of the European Observatory on Health Systems and Policies. Copenhagen; Forthcoming 2012.

2 Barriball L, Bremner J, Buchan J, Craveiro I, Dieleman M, Dix $\mathrm{O}$, et al. European Commission recruitment and retention of the health workforce in Europe - final report. European Commission: Luxembourg; 2015.
3 Lorant V, Geerts C, D'hoore W, Sauwens D, Remmen R, Peremans $\mathrm{L}$, et al. Médecine générale: comment promouvoir l'attraction et la rétention dans la profession [Making General practice attractive: encouraging GP attraction and retention. Health services research (HSR)]. Bruxelles: Belgian Health Care Knowledge Center; 2008. Report No.: KCE reports $90 \mathrm{~B}$.

4 FOREM. Métiers en pénurie [Internet]. 2016 [cited 2016 Sep 1]. Available from: https://www.leforem.be/particuliers/metiers-porteursliste.html

5 Meeus P, Van Aubel X. Performance de la médecine générale, bilan de santé [Performance of general medicine in Belgium, a check-up. health services research (HSR)]. Bruxelles: Belgian National Institute for Health and Disease Insurance (NIHDI); 2012.

6 Cellule Planification des professions de soins de santé, Service Professions des soins de santé et pratique professionnelle, DG Soins de santé [Health Care Professions Planning Unit, Health Professions and Professional Practice, Health Care Directorate. PlanCAD Physicians 2004-2012]. PlanCAD Médecins 2004-2012. SPF Santé Publique, Sécurité de la chaîne alimentaire et Environnement [FPS Public Health, Food Chain Safety and Environment]; 2015 mai.

7 Dale J, Potter R, Owen K, Parsons N, Realpe A, Leach J. Retaining the general practitioner workforce in England: what matters to GPs? A cross-sectional study. BMC Fam Pract. 2015;16(1):140.

8 Van baelen S, Goedhuys J, Heyrman J, Stroobants R, Minguet C. Het beroep van huisartsen die in 1995 afstudeerden [The profession of GPs graduated in 1995]. Tijdschr Voor Geneeskd. 2003;59(20):1216-24.

9 Lorant V, Artoisenet C, Violet I. Pourquoi certains médecins abandonnent-ils la profession? [Why do some doctors abandon the profession?]. Healthc Exec. 2007 juin.

10 Schoenmakers B, Aertgeerts B, Buntinx F, Vankrunkelsven P, Van PottelBerg G, De Lepeleire J. De Vlaamse huisarts anno 2013:op kruissnelheid naar verandering [The Flemish GP anno 2013: cruising speed to change]. Tijdschr Voor Geneeskd. 2014;70(12):657-65.

11 Hedden L, Barer ML, Cardiff K, McGrail KM, Law MR, Bourgeault IL. The implications of the feminization of the primary care physician workforce on service supply: a systematic review. Hum Resour Health. 2014;12:32.

12 Lapeyre N, Feuvre NL. Féminisation du corps médical et dynamiques professionnelles dans le champ de la santé [Feminization of the medical profession and professional dynamics in the field of health]. Rev Fr Aff Soc. 2005;(1):59-81.

13 Lapeyre N, Robelet M. Les mutations des modes d'organisation du travail au regard de la féminisation. L'expérience des jeunes médecins généralistes [The changing patterns of work organization regarding feminization. The experience of young general practitioners]. Sociol Prat. 2007 Mar 1;14(1):19-30.

14 Denekens JPM. The impact of feminisation on general practice. Acta Clin Belg. 2002 Feb;57(1):5-10.

15 Dwan KM, Douglas KA, Forrest LE. Are 'part-time' general practitioners workforce idlers or committed professionals? BMC Fam Pract. 2014 Sep;15(1):154.

16 Bloy G. transmission des savoirs professionnels en médecine générale: le cas du stage chez le praticien [The transmission of professional knowledge in general medicine: the case of practitioner training]. Rev Fr Aff Soc. 2005 Mar 1;(1):101-25.

17 Jean O, Leloup M, Vardon D, Fanello S. Activités médicales hors cabinet des médecins généralistes [Medical activities outside the general practitioner's office]. Santé Publique. 2010 Jan 18;21(5):453-64.

18 Bloy G. Comment peut-on devenir généraliste aujourd'hui ? Le renouvellement des médecins généralistes vu à travers une cohorte de jeunes diplômés [How can one become a generalist today? The renewal of general practitioners seen through a cohort of young graduates]. Rev Fr Aff Soc. 2011 Dec 16;2-3(2):9-28.

19 Delansorne F, Buis H, Robino S, Tomas J, Huez J-F, Fanello S. Cessations anticipées d'activité des médecins généralistes libéraux dans les trois départements de l'ouest de la France [Early suspension of private practice: the current trends for general practitioners in three counties in western France Santé Publique]. Quelle réalité ? Santé Publique. 21(4):375-82.

20 Hann M, Reeves D, Sibbald B. Relationships between job satisfaction, intentions to leave family practice and actually leaving among family physicians in England. Eur J Public Health. 2011 Aug;21(4):499-503. 